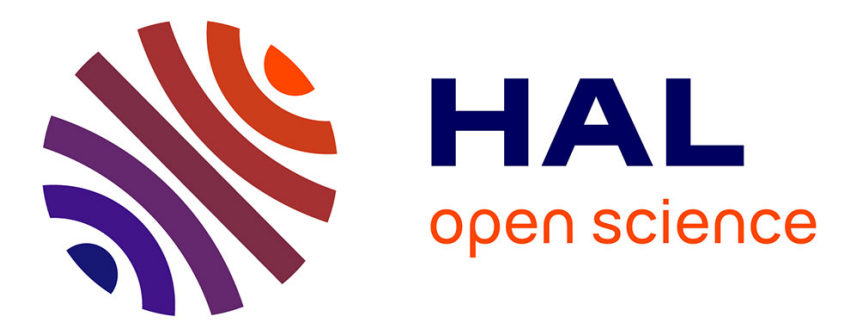

\title{
Patients with lung cancer: are electronic cigarettes harmful or useful?
}

Bertrand Dautzenberg, Daniel Garelik

\section{To cite this version:}

Bertrand Dautzenberg, Daniel Garelik. Patients with lung cancer: are electronic cigarettes harmful or useful?. Lung Cancer, 2016, 10.1016/j.lungcan.2016.05.011 . hal-01321856

\section{HAL Id: hal-01321856 \\ https://hal.sorbonne-universite.fr/hal-01321856}

Submitted on 26 May 2016

HAL is a multi-disciplinary open access archive for the deposit and dissemination of scientific research documents, whether they are published or not. The documents may come from teaching and research institutions in France or abroad, or from public or private research centers.
L'archive ouverte pluridisciplinaire HAL, est destinée au dépôt et à la diffusion de documents scientifiques de niveau recherche, publiés ou non, émanant des établissements d'enseignement et de recherche français ou étrangers, des laboratoires publics ou privés. 
Review

\section{Patients with lung cancer: are electronic cigarettes}

\section{harmful or useful?}

Bertrand DAUTZENBERG ${ }^{\text {ab }{ }^{*},}$ Daniel GARELIK ${ }^{\mathrm{b}}$

a Unité tabac Service de Pneumologie et réanimation respiratoire, Hôpitaux Universitaires Pitié

Salpêtrière - Charles Foix (APHP), Paris, France

b Université Pierre et Marie Curie (upmc, Paris 6), France

c Paris Sans Tabac (PST); France

* Corresponding author. Tel.: +331421677 70.

E-mail addresses: bertrand.dautzenberg@aphp.fr (B. Dautzenberg). 


\title{
Highlights
}

- E-cigarettes should never be assumed to be totally safe: they are not recommended for use by people who have never smoked, unless as an alternative to starting to smoke

- The emissions of e-cigarettes contain no tar and have less than one percent of the nitrosamines of tobacco smoke

- In normal use, aldehydes are less than ten percent of the levels found in tobacco smoke.

- A complete replacement of smoking by e-cigarette use offers the nicotine user a dramatic decrease in the risk of serious diseases

- The option to switch to e-cigarettes should be considered by healthcare practitioners with patients with cancer who would otherwise continue to smoke.

\section{Key words}

- Electronic cigarette

- Smoking

- Adverse effect

- Smoking reduction

- Smoking cessation

- Lung cancer patient

\begin{abstract}
E-cigarettes remain controversial because the scientific evidence of short term and long term effects on tolerance and the health value of a switch from tobacco to e-cigarettes is contested and controversial. Nevertheless the quality of e-cigarettes and e-liquids has improved. The main ingredients, propylene glycol,
\end{abstract}


vegetable glycerine and nicotine are pharmaceutical-grade quality in most e-liquids. Flavors are almost all food grade. The high quality of ingredients has decreased the presence of impurities in e-liquids.

The emissions of e-cigarettes do not contain solid particles or carbon monoxide. Nitrosamine content is at least one hundred times lower than in tobacco smoke. E-cigarette emissions in normal use do not contain any harmful constituents at significant levels except nicotine. UK public health authorities have stated that e-cigarette use is likely to be at least $95 \%$ less toxic than cigarette use.

There are benefits from having a well-regulated legal market. In countries where e-liquid containing nicotine is not allowed, "do-it-yourself" liquids are common and have handling risks and may sometimes contain toxic impurities. Though e-cigarettes should never be assumed safe products for non-smokers, for smokers, the e-cigarette is at least 20 times less dangerous than the cigarette. Tobacco cessation specialists in countries where nicotine containing e-cigarettes are available increasingly provide counselling for e-cigarette use to stop smoking or to reduce smoking at the request of patients. Based on current knowledge, for patients with lung or other forms of cancer who would otherwise continue to smoke, e-cigarettes offer an alternative way to quit smoking while they undergo medical treatment.

\section{Text}

\section{Introduction}

\subsection{Tobacco kills}

Any evaluation of e-cigarettes should consider the risks associated with smoking, which kills one out of two smokers [1]. Tobacco smoke killed 100 million smokers during the twentieth century [2]. It is the main preventable cause of death worldwide [3]. Anything that can reduce tobacco smoking can contribute to public health. The tobacco industry has designed its products to maintain the addiction of its customers and initiate teenagers into "tobacco dependence disease" [4]. Faced with tobacco lobbies, the nations of the World Health Assembly have established the Framework Convention on Tobacco Control (FCTC) which had 180 state parties in 2015 [5]. 


\subsection{The emergence of e-cigarettes}

The e-cigarette has profoundly changed the landscape of the fight against smoking, but it cannot address every aspect of the problem. It should be integrated within the spectrum of tobacco products and medications (NRT) with different risks and effectiveness as alternatives to cigarette smoking.

In this review, we focus on useful factual information about e-cigarettes for professionals who deal with lung cancer patients.

\section{Origins and nature of e-cigarettes}

\subsection{History}

After first experiments with nebulization of nicotine fifty years ago [6], the e-cigarette was invented by a pharmacist Hon Lik. The first 2006 US patents defined a product that works by nebulization. Now e-cigarettes work by vaporization of a liquid and creation of an aerosol of fine nicotine-containing droplets.

\subsection{What is an e-cigarette?}

The electronic cigarette (e-cigarette), or "personal vapor device" or electronic nicotine delivery system (ENDS) is an emerging product that is neither a tobacco product nor a smoking cessation medication. It is a consumer product that blurs the boundaries between tobacco products and NRT [7]. In the EU, all countries will regulate this new product under the Tobacco Products Directive 2014/40/EU from May 2016 [8].

The product is comparatively recent and the early e-cigarette technology had poor nicotine delivery and was, therefore, a poor substitute for smoking. Remarkable progress has been made over the last four years and now the majority of e-cigarettes are effective nicotine delivery devices. The product has been largely used in US and in Europe where 13\% of EU citizens (and 21\% of French adults) had tried the product and $2 \%$ were using it on a daily basis in December 2014 [9]. 


\subsection{General principle of vaporization}

The principle of operation is based on passing the e-liquid over a heating coil (atomizer) supplied in a regulated manner by a battery. A solvent base of propylene glycol (PG) or glycerol (vegetable glycerine VG) is transformed from liquid state to aerosol state (vaporization) when heated by the atomizer. The aerosol is formed of fine droplets whose visual appearance can be similar to tobacco smoke or clouds. Scientifically this aerosol of fine droplets is not a vapor (i.e. a gas) but the word "vapor" is commonly used to describe the aerosol.

\section{The e-cigarette device}

\subsection{E-cigarette types}

All e-cigarettes operate on the same general principle. E-cigarette devices available on the market are of three broad types:

- first generation of e-cigarettes (cig-a-like) imitated the real tobacco cigarette in appearance.

- second generation e-cigarettes had the shape of large pen and are refillable.

- third generation e-cigarettes are completely modular (called 'mods', or 'tanks and mods') with separate batteries and atomisers. They bear no resemblance to tobacco products.

Other electronic nicotine delivery devices, such as e-shisha and e-pipes also operate on similar principles.

An e-cigarette may include (Fig.1):

- A disposable or rechargeable battery.

- A pressure-sensitive sensor in the mouthpiece or a switch to activate heating of the device.

- An electronic control system with varying degrees of sophistication, allowing for control of power and battery charging and, more recently, control of coil temperature, and sometimes data on usage.

- A tank that holds the e-liquid, sometimes known as a clearomiser or cartomiser.

- A wick that directs the liquid to the heating element.

- An atomiser containing a heating coil in which the 'vapor' (aerosol) is produced. 
- A mouthpiece through which the user draws the vapor.

- Decorative features such as LEDs or ornate patterns and designs. It is now rare to have simulated glowing red tips on products, though this was a feature of early cig-a-likes.

fig 1

\subsection{First generation - the cig-a-like}

These e-cigarettes are shaped like cigarettes and are sometimes packaged in the same way as cigarettes. Some models had red or blue LED glowing tips to either imitate or differentiate them from tobacco cigarettes respectively. The heating of vapor is almost always triggered by inhalation pressure. The battery is often disposable single use and the amount of e-liquid allows for 50 to 200 puffs. These e-cigarettes are often marketed by the tobacco industry. They especially offer smokers to ability to continue taking nicotine puffs where smoking is prohibited. There are variations on this basic model with rechargeable batteries and e-liquid cartridges that are compatible with a specific branded device.

\subsection{Second generation - the 'pen' type}

Second generation e-cigarettes are refillable devices from small $10 \mathrm{ml}$ or larger e-liquid vials or cartridges. The battery is rechargeable. The puff triggering is mostly manual by pressing a switch. The screw for assembling the part containing the battery and the vaporization chamber is standardized. The electronic control sometimes allows the user to change the electrical power applied to the heating coil.

\subsection{Third generation - tanks and mods}

This term 'mods' refers modular vaping devices, where the power supply is separate from the rest of the device - the 'tank'. It can include large or small form batteries, a vast range of atomizer chambers of variable designs, usually made from steel and borosilicate glass and usually electronic control over power 
output and increasingly over coil temperature. The tanks and mods combinations and settings are endless. Often the air flow can be regulated to obtain a large puff volume by addition of fresh air.

\subsection{Hazards related to the e-cigarette device}

The devices have risks independent of the e-liquid:

- Electrical safety. The batteries of electronic cigarettes, as any advanced battery, can overheat and explode, usually as a result of a short circuit or through use of incompatible chargers [10]. These accidents are rare, but as for a mobile phone if overheating occurs, with hissing noises or deformation of the tank, users should be advised to stay away from the device as they would move away from a firecracker after lighting. All consumers should be made aware of this risk.

- Physical safety. Following any serious impact on the device, it should be checked for e-liquid leaks and any damaged components changed.

- Chemical safety. There is a danger that some material from the device could leach into the liquid. The safest choice is glass rather than plastic components. Hazardous monomers such as bisphenol A or metals could be released from some plastics used for the mouthpiece and parts in contact with the e-liquid.

- Operational safety. Another potential harm is related to the complexity of modular devices. Some sophisticated settings should be used only by experienced users and never by beginners who should be advised to begin with the simplicity of a second generation e-cigarette.

\section{E-liquids}

\subsection{Composition of the e-liquid}

The inhaled aerosol will be chemically similar to the e-liquid itself as there are no combustion processes, so the user should be advised to purchase good quality liquids with reputable brands and suppliers. 
E-liquids mainly contain five ingredients:

- Diluent base represents $70-90 \%$ of the product. Propylene glycol (PG) and/or vegetable glycerine (VG). All reputable e-liquids will use pharmaceutical grade PG and VG, which will avoid impurities like ethylene glycol. The 80/20 PG/VG e-liquids are the most common, they bring PG transmission characteristics and good aromas. VG is mostly used to affect the appearance of the vapor cloud to create a similar appearance to tobacco smoke. By increasing VG to 50/50 the ratio, the vapor cloud is more visible and persistent, but the device needs to be carefully chosen because the high viscosity of VG can create wicking problems in some devices.

- Food grade or tobacco flavors are usually diluted in PG, usually between 2 and $12 \%$ of the total.

- Alcohol of alimentary quality usually between $1.2^{\circ}$ and $8^{\circ}$, if present.

- Water at high purity (0 to $10 \%)$.

- Nicotine in concentrations from 0 to $4.8 \%$, i.e. 0 to $48 \mathrm{mg} / \mathrm{mL}$ for widely available liquids of pharmaceutical grade quality (>99.5\%). Under the EU Tobacco Products Directive, $20 \mathrm{mg} / \mathrm{mL}(2 \%)$ nicotine will be the maximum permissible concentration for e-liquid sold outside the pharmaceutical system [8].

Some e-liquid contains others ingredients at low concentration usually less than $10 \%$. The list of the ingredients has to be displayed on the e-cigarette or e-liquid packaging in decreasing concentration order.

\subsection{Quality of e-liquid}

In France, the AFNOR standard XP90-300 [11] specifies which ingredients should not be used, and various possible interactions between the containers and contents. Storage conditions are specified and the nicotine levels displayed on the packaging must be accurate to within 5\%. A "non-nicotinic" liquid must contain $\leq 0.05 \%$ nicotine. Ingredients classified CMR (Carcinogenic-Mutagenic-Reprotoxic) may not be used in e-liquid under this standard. Energizing compounds as taurine, caffeine are also excluded [11]. At European Union level, the CEN (European Committee of Standardization) has started work on a harmonized EU standard, and plans to conclude in 2017-2018. 


\subsection{Hazards related to e-liquid before vaporization}

Risks of e-liquid before vaporization are:

- Chemical interaction between the e-liquid and its container or the tank the e-cigarette.

- The spillage of e-liquids containing nicotine while refilling e-cigarette tanks with the risk of e-liquid exposure to the eyes, skin or mucosa.

- Accidental ingestion by children or by adults. Among children one fatal case has been reported with a high concentrate of nicotine use to prepare do-it-yourself e-liquid [12] and non-fatal cases have been reported also with e-liquid in children [13-14]. Nicotine liquids have been used in adult suicide attempts: [15-16], one attempt failed with $1500 \mathrm{mg}$ [17] but another succeeded with $10000 \mathrm{mg}$ (equivalent of 50 tanks of high concentration e-liquid [18]. All e-liquid bottle caps need to be child resistant. Clear communication of the risk to children and in handling nicotine liquid containers has to be provided. Advice about refilling has to be made simple for beginners recommending use of a table with eye glasses, gloves and paper on the table.

- In some countries that prohibit e-liquids with nicotine, an underground network has formed to supply e-liquids. This could be illicit cross-border trade in conventional high quality products but may also supply liquids with other substances such as caffeine, illegal substances such as prescription medications or cannabis extracts, and may contain impurities as ethylene glycol or metals.

- When e-liquid is distributed in the EU, the exact composition of the e-liquid has to be declared by the responsible company before marketing in EU countries according to the REACH regulation $n^{\circ} 1907 / 2006$.

- E-liquids containing nicotine may be covered by the CLP regulation (Classification, Labelling and Packaging $=$ regulation $\left.\mathrm{n}^{\circ} 1272 / 2008 / \mathrm{CE}[19]\right)$. This is the European Union implementation of the Globally Harmonized System of Classification and Labelling of Chemicals. Pure nicotine is listed as a dangerous substance, but the implementation for diluted e-liquids remains subject to discussion because of the interpretation of the animal studies used for calculation of lethal 
dose. According to existing data and CLP classifies oral nicotine use as non-toxic. Nevertheless some regulators have asked for a skin or ingestion classification of e-liquid containing 10 or 20 $\mathrm{mg} / \mathrm{mL}$ A clarification is awaited.

\section{Ingredients in e-liquid emissions}

\subsection{Physical composition of emissions}

The emission from an e-cigarette is an aerosol that contains small liquid droplets forming from the heated e-liquid and some gas. The median size of droplets is 0.10 to $0.18 \mu$ (CMAD). The mass distribution of e-liquid rich in VG has higher MMAD then PG based e-liquids (250-650 $\mu)$ [20-23]].

The half-life of vapor droplets is very short (11 seconds for PG e-liquid $28 \mathrm{sec}$ for VG e-liquid [7]). The size of droplets decreases during the inspiration phase and exhaled droplets are smaller explaining the high level of nicotine delivery because of vaporization of droplets during the respiratory tract transit. The 'particulate matter' of e-cigarette vapor is sometimes referred to, but this refers to liquid-state droplets rather than solid particles. Any comparisons and projections based on effects of conventional solid particulate matter are mainly a confusion [24].

\subsection{Chemical composition}

Some emissions from poor quality e-cigarette devices, or through use at excessively high temperature, may contain high levels of impurities or harmful thermal decomposition substances, but the vast majority of chemical characteristics of e-cigarette emissions are those of the original ingredients of the e-liquid with no chemical transformation during vaporization. This is very different to tobacco cigarettes where the emissions are the product of combustion, created by burning the tobacco, and include carcinogenic tars such as benzopyrene, sub-micronics irritants particles and gases, and carbon monoxide which is in competition with oxygen in the blood, muscles and brain. All these compounds are absent in e-cigarette emissions because there is no combustion [25]. 
- The diluent PG/VG base is found in emissions in proportions similar to those used in e-liquid and without chemical transformation. PG and VG do not cause severe short term or medium term side effects. Propylene glycol is used in many medications, including anti-asthma drugs. But long term consequences of prolonged exposure to these compounds cannot yet be assessed.

- If present in the e-liquid, alcohol will be present in the emissions. The typical intake per day is 2-4 $\mathrm{mL}$ with $1.2^{\circ}-8^{\circ}$ alcohol, which corresponds to the intake of a tea spoon of beer every day. Nevertheless such liquid containing alcohol has to be labelled.

- The food flavors used in e-liquids are tested for heating and for oral use [25], but not for inhalation. User surveys do not signal strong grounds for public health concern, but some animal studies show an inflammatory effect of aroma mixture. Analyses revealed that the cytotoxicity of e-liquid is directly correlated to the amount and the number of flavoring agents contained in them [26]. The flavorings used in e-liquids may be natural or artificial in origin and associated with an aroma carrier. There are hundreds of flavors, the most popular being tobacco, mint, fruit, coffee, vanilla and chocolate.

Cinnamon extracts appear to increase cytotoxicity in e-liquid [27-28].

Some flavorings contain diacetyl, which is used to give a buttery taste. It is naturally derived from certain fermentation processes. Diacetyl exposure may cause irritation of the mucous membranes (nose, throat and eyes) and airway. Cases of bronchiolitis obliterans incriminating diacetyl were found in employees of popcorn production industry in 2000 [29-30]. The "greedy" aromas (cookies, candies ...) frequently contain diacetyl and sugars.

There is a list of permitted food flavors and these are authorized with ingestion limit values set by the European Commission [31] and the FDA, but there is no guarantee of safety for inhalation use.

Some components of aromas are known allergens: ethyl vanillin, eugenol, limonene, benzyl alcohol, anise alcohol and are found in several e-liquids [32]. 
Nicotine delivery was poor in devices available before 2010 [33-35]. With more recent e-cigarettes, more than $60 \%$ of the nicotine entering the vaporization chamber is found in blood then recovered in urine as cotinine [36]. The high proportion absorbed implies a partial oral deposit and absorption and a good absorption of the nicotine contained in the aerosol during the time of pulmonary passage. The best e-cigarettes are now much more effective in delivery of nicotine, and comparable to the tobacco cigarette. Optimal nicotine delivery is important because it is necessary to make e-cigarettes a viable alternative to smoking. Data are lacking, but it is clear that the absorption of nicotine is slower with e-cigarettes than with tobacco cigarettes, but faster than for oral NRT or shisha.

A cigarette smoker typically takes 300 puffs per day (15 puffs within 10 minutes of each of the 20 cigarettes of the package) inducing high peaks of nicotine. The e-cigarette user takes 200-300 puffs regularly distributed from the morning to the night, ensuring a regular supply of nicotine as with NRT patches. New users will typically need an $18-20 \mathrm{mg} / \mathrm{mL}$ nicotine e-liquid to provide a good throat hit, but users who have stopped smoking for several months will manage with a lower nicotine concentration, typically $9-11 \mathrm{mg} / \mathrm{mL}$ and may gradually drop to $4-8 \mathrm{mg} / \mathrm{mL}$.

\section{Impurities in emissions}

Impurities may come from contaminants in e-liquid, from leaching of materials in the e-cigarette device and from the transformation of e-liquid by thermal decomposition. However, the e-cigarette emissions contain no toxic substances associated with combustion such as carbon monoxide, tar or solid fine particles. A UK official health organization states that e-cigarette use is likely to be at least $95 \%$ less harmful than tobacco smoking [37].

\subsection{Acrolein}

Acrolein in e-cigarette emissions is between 0.7 and $4.19 \mathrm{mg}$ for 150 puffs, 15 to120 times lower than the cigarette smoke in normal vape condition; with "dry puffs", however, this rate is 2 times higher than in 
conventional cigarette smoke [38-39]. Users should be advised that the occurrence harsh acrolein odor is the consequence of improper use of the device. Users will in any case stop automatically because of the taste.

\subsection{Acetaldehyde}

In normal use, the daily emission of acetaldehyde is typically $<20 \mu \mathrm{g}$ for 200 puffs when breathing in a room with acceptable ambient air pollution by acetaldehyde conduct to inhale $1920 \mu \mathrm{g}$ of acetaldehyde [40]. The acetaldehyde as others aldehydes is formed in case of overheating and dry conditions.

\subsection{Formaldehyde}

Formaldehyde is an irritant, classified as carcinogenic and regulated in ambient air and at workplace in many countries. IARC has classified formaldehyde as a carcinogen (Group 1) mainly for cancers of the nasopharynx. Formaldehyde is not present (or at trace level) in e-liquid but is formed by excessive heating of the e-liquid. The daily emission of formaldehyde is typically 3.2-56 $\mu$ g for 200 puffs [38-39] when breathing in a room with acceptable ambient air pollution by formaldehyde conducts to inhale $120 \mu \mathrm{g}$ of formaldehyde [41].

Many others papers report a low level of formaldehyde in normal e-cigarette use but a high level of formaldehyde when overheating creates 'dry puff' conditions.

\subsection{Dry puff and overheating conditions}

The formation of aldehydes and other thermal decomposition products in the vapor arises when the coil becomes overheated and pyrolysis occurs. This has been measured in several experimental conditions [38, 42], In normal use when the resistance is fully surrounded with e-liquid and the atomiser ventilated the vaporization of PG or VG prevent overheated who may occur only if a too high electric power is applied to the surface of the resistance, a lack of e-liquid or a misuse of the device as dry puff procedure. Machines cannot taste the liquid so do not have this protective control feedback. In the real world, human subjects do not experience significant exposure because the presence of these products creates a harsh acrid taste which vapers recognize as 'dry puff' and will stop vaping [39]. 


\subsection{Metals}

Metals are present only at trace levels in e-liquids.

The presence of metal residues in emissions is mainly related to a degradation of metallic parts of the e-cigarette body because of poor choice of materials by manufacturers or misuse by users. The amount of metal exposure from an e-cigarette with 200 e-cigarette puffs remains far below the maximum level permitted for daily intake by inhalation of medication [43].

\section{Risk of high temperature}

The risk of burning through contact with hot parts of the device is much less likely than accidental burns with tobacco cigarettes. Emissions of e-cigarette have a maximum temperature of 60 degrees at the mouthpiece and it is possible that some parts of the surface of a device may become hot.

For modular devices, where it is possible to attach a high voltage battery to a coil not designed for high power there should be clear labelling of the maximum voltage recommended by the manufacturer for the specific coil resistance. Some systems are equipped with memory that allows data to be collected and transferred on the start and duration of each puff to a cell phone or a computer [44]. Voltages of more than 4 or 5 volts should be applied only to low resistance coils or to dual systems (double coils).

\section{Comparison of e-cigarette emissions and tobacco smoke}

- Inhalation of conventional cigarette smoke produces a significant peaks of nicotine into the brain. The peak of nicotine occurs in 7-8 seconds and quickly saturates the relevant brain receptors' binding capacities, producing multiplication and desensitization of receptors, maintaining a high level of nicotine dependence. The e-cigarette has a slower transit of the nicotine to the brain. A very regular distribution of puffs [39] throughout the day results in a steady state of nicotine in blood. Without nicotine peaks, the number of brain receptors slowly decreases in 2 or 3 months. 
- The main carcinogens found in tobacco smoke are in the complex residue known as 'tar' or gaseous products of tobacco combustion and include, polycyclic aromatic hydrocarbons, nitrosamines, aldehydes and heavy metals. Tar is not released by e-cigarettes, whereas emissions from a pack of cigarettes contain 200-600 mg of tars. Nitrosamines exposures are more than 100 times lower in e-cigarette emissions than in cigarette smoke. The acrolein and aldehydes such as formaldehyde have much lower emission concentration in e-cigarettes than in tobacco smoke [38-39].

\section{Others risks of e-cigarettes}

\subsection{Passive vaping}

The source of environmental tobacco smoke is mainly due to the emission of tobacco smoke between puffs. With e-cigarette there is no emission between puffs. The half-life of e-cigarette emissions is brief compared with cigarette smoke whose solid particles persist longer in rooms where people smoke, but as with active smoking, e-cigarette emissions products persist in gaseous form [32].

With e-cigarettes there are no risks associated with solid particles or carbon monoxide $(\mathrm{CO})$ but nicotine persists in the air and can be detected as cotinine in the urine of persons in contact. The risks of this passive vaping remain unknown. The risk of passive vaping is probably much lower compared to that of passive smoking but further study is needed.

\subsection{Risks for public health}

The idea of clean tobacco has been used for years by the tobacco industry to gain acceptability of tobacco in our society. The e-cigarette should not be used restore a place for tobacco in our society and in particular should not be a gateway or a way to return to tobacco use. While there may be significant opportunities with e-cigarettes there are also threats, justifying the continuing vigilance of public health stakeholders. 


\section{What recommendation should health professionals make about e-cigarettes to lung cancer patients?}

\subsection{The tobacco dependence, a disease to be treated}

In absence of a full medicinal evaluation or complete evidence base, the health professional has to make decisions based on clinical experience with smokers and e-cigarette users and based on the data and that is available. It is known that, for this specific population, smoking worsens the outcome of surgery [45-46], may decrease the benefit of radiotherapy [47-48], may alter the effects of the chemotherapy and increases side effects [49], increases the risk of progression [49] and the risk of a second carcinoma [50-53], decreases the efficacy of a palliative therapy and decreases the quality of life [54]. Treating tobacco dependence in this situation is a part of global treatment of lung cancer. E-cigarettes could be a pleasurable, and hence viable, way to quit tobacco in patients who continue to smoke while suffering with lung cancer. The benefits of e-cigarette are questioned by some authors [55-56], but e-cigarettes may play a role in patients with cancer [57-59].

The American Cancer Society in 2015 was reluctant to support e-cigarette use in patients with cancer because of the lack of studies [60]. The International Association for the Study of Lung Cancer in 2014 was a little more open [61]. In France, an experts' task force proposed in 2014 a strategy for practitioners to integrate e-cigarettes in the assistance of patients trying to quit tobacco [62].

\subsection{Advice to a non-smoker or long-term former smoker}

The health professional's advice will always be to discourage use by non-smokers because the e-cigarette, although much less dangerous than cigarettes, is not healthy and could cause or reignite nicotine dependence.

\subsection{Advice to a persistent smoker with lung or other cancer}

To a smoker who wants to stop and asks for the doctor's opinion on using an e-cigarette, the health professional has to: 
- Accept this choice.

- Explain the need to find the right e-liquid to experience an optimal throat hit, with a sensation in the throat similar to that of tobacco by challenge of several products. Recommend to start the use of a refillable second generation device or a device without sophisticated settings.

- Counsel to buy their first products in the shop and ask the assistant for technical advice.

- Consider having two e-cigarettes to cope with any failure or incidents that may induce early relapse to tobacco.

- See the smoker again 7-14 days later.

\subsection{To a dual user (e-cigarette + tobacco use)}

The health professional has to:

- Analyze the pattern of consumption, which in the short term represents a possible solution to reduce the risk, but in long term could often lead to a relapse to be exclusively a smoker again. For these patients, the health professional could be the most useful counsellor, for example suggesting increasing the dose of non-tobacco nicotine to move them towards exclusive e-cigarette use.

- Consider the addition of a NRT patch, ask the patient to use it regularly all day along with e-cigarettes so as to never experience nicotine withdrawal as long as the craving to smoke persists.

- Analyze the last 3-5 cigarettes consumed, which are often smoked for reasons than nicotine dependence and try to fight against these last cigarettes one by one.

\subsection{To a long term e-cigarette user with lung or other cancer}

- If they are not zero, the risks of long-term use of e-cigarettes are far lower than the continuation of smoking; so it is recommended to accept the long term use of e-cigarettes in these patients during the first 1-3 years.

- As long as the risk of relapse of tobacco is high, health professionals should encourage further e-cigarette use and consider a decrease or a cessation of e-cigarette use only 2-3 months after the 
last tobacco cigarette, but if the cessation of e-cigarette use occurs three years later, it is not a severe problem.

Table 1

\subsection{In special situations}

- During the surgery period, smoking increases local and general risks. E-cigarette use is always better than smoking and its risks are probably almost the same as those of NRT, almost zero.

- During a radiotherapy period, intensive smoking increases the combination of $\mathrm{CO}$ on haemoglobin and decreases the transport of oxygen when hypoxemia decreases the efficacy of radiotherapy. E-cigarette emissions do not contain any $\mathrm{CO}$.

\section{Conclusion}

E-cigarettes are a new product fitting between pharmaceutical products and tobacco products that are likely to be far less harmful than smoking but for which there is the lack of long-term prospective study. But year after year, the products have improved in quality and nicotine delivery. The intervention of health professionals could increase the number of smokers who switch to e-cigarette. The benefit of this switch is important in patients with lung or others cancers, so health professionals who treat lung conditions should be informed about e-cigarettes and prepared to discuss not only uncertain risks and hypothetical side effects, but also the benefits for a smoker to switch from inhalation of tobacco smoke to e-cigarette vapor [63].

\section{Conflict of interest statement}

The authors declare no conflicts of interest connected to publication of this manuscript.

\section{Funding}

No funding supported this work. 


\section{References}

1. Doll R, Peto R, Boreham J, Sutherland I. Mortality in relation to smoking: 50 years' observations on male British doctors. BMJ : British Medical Journal, 2004; 328: 1519-25

2. Eriksen M, Mackay J, Schluger N, Gomeshtapeh FI, Drope J. Tobacco atlas. Fifth edition 2015 American Cancer Association http://www.tobaccoatlas.org

3. WHO fact http://www.who.int/tobacco/mpower/tobacco_facts/en/

4. Proctor RN. Golden Holocaust: Origins of the Cigarette Catastrophe and the Case for Abolition, 2012

5. FCTC Framework Convention against tobacco http://www.who.int/fctc/en

6. Gilbert HA. Us Patents 3200819 smokeless non-tobacco cigarette http://www.google.com/patents/US3200819

7. Dautzenberg and OFT experts: Rapport et avis d'experts sur l'e-cigarette, OFTa 2013212 pp, Paris, French. http://www.ladocumentationfrancaise.fr/var/storage/rapports-publics/134000328.pdf

8. European Commission and European Council. Directive 2014/40/UE on tobacco product. http://ec.europa.eu/health/tobacco/docs/dir 201440 en.pdf

9. European Commission. Eurobarometer 429 attitudes of Europeans towards tobacco and electronic cigarettes, 2015 [fieldwork December 2014] http://ec.europa.eu/public_opinion/archives/ebs/ebs_429_en.pdf

10. U.S. Fire Administration Electronic Cigarette Fires and 2014. https://www.usfa.fema.gov/downloads/pdf/publications/electronic cigarettes.pdf

11. AFNOR norm XP90-300 e-cigarette and e-liquids AFNOR france2015

12. Shawn, L. and L.S. Nelson, Smoking cessation can be toxic to your health. Emergency Medicine, 2013.;45:7-9

13. Gill N, Sangha G, Poonai N, Lim R. E-Cigarette Liquid Nicotine Ingestion in a Child: Case Report and Discussion. CJEM. 2015;17:699-703

14. Gupta, S., A. Gandhi, and R. Manikonda, Accidental nicotine liquid ingestion: emerging paediatric problem. Arch Dis Child, 2014; 99: 1149. 
15. Chatham-Stephens, K., et al., Notes from the field: calls to poison centers for exposures to electronic cigarettes--United States, September 2010-February 2014. MMWR Morb Mortal Wkly Rep, 2014. 63: 292-3.

16. Bartschat, S, Mercer-Chalmers-Bender K, Beike J, Rothschild MA, Jübner M. Not only smoking is deadly: fatal ingestion of e-juice-a case report. Int J Legal Med. 2015;129: 481-6. doi: 10.1007/s00414-014-1086-x.

17. Christensen, L.B., T. Van't Veen, and J. Bang. Three cases of attempted suicide by ingestion of nicotine liquid used in $\begin{array}{lllll}\text { e-cigarettes. } & \text { in } & \text { Toxicology. } & \text { 2013; } & 51: 290\end{array}$ http://www.eapcct.org/publicfile.php?folder=congress\&file=Abstracts_Copenhagen.pdf

18. Thornton SL, Oller L, Sawyer T Fatal intravenous injection of electronic nicotine delivery system refilling solution. $\mathrm{J}$ Med Toxicol, 2014; 10: 202-4.

19. European Regulation (EC) No $1272 / 2008$ on classification, labelling and packaging of substances and mixtures 2009 http:/ec.europa.eu/enterprise/sectors/chemicals/documents/classification/index en.htm\#h2-1

20. Bertholon JF., Becquemin MH, Roy M, Roy F, Ledur D, Annesi, Maesano I et al Comparison of the aerosol produced by electronic cigarettes with conventional cigarettes and the shisha. Revue Maladies Respiratoires 2013; 30: 752-7.

21. Zhang Y, Sumner W, Chen D-R. In vitro particle size distributions in electronic and conventional cigarette aerosols suggest comparable deposition patterns. Nicotine Tob Res. 2013;15:501-8.

22. Fuoco FC, Buonanno G, Stabile L, Vigo P. Influential parameters on particle concentration and size distribution in the mainstream of e-cigarettes. Environ Pollut. 2014;184:523-9.

23. Ingebrethsen BJ, Cole SK, Alderman SL. Electronic cigarette aerosol particle size distribution measurements. Inhal Toxicol. 2012;24:976-84.

24. Manigrasso M, Buonanno G, Fuoco FC, Stabile L, Avino P. Aerosol deposition doses in the human respiratory tree of electronic cigarette smokers. Environ Pollut. 2015;196: 257-67.

25. Long, GA; Comparison of Select Analytes in Exhaled Aerosol from E-Cigarettes with Exhaled Smoke from a Conventional Cigarette and Exhaled Breaths. Int J Environ Res Public Health, 2014; 11: 11177-91.

26. Bahl V, Lin S, Xu N, Davis B, Wang Y, Talbot P. Comparison of electronic cigarette refill fluid cytotoxicity using embryonic and adult models. Reprod Toxicol Elmsford N. 2012;34:529-37. 
27. Farsalinos KE, Romagna. Cytotoxicity of cinnamon-flavored electronic: are the results truly applicable? 2014;28:1016-7.

28. Behar RZ, Davis B, Wang Y, Bahl V, Lin S, Talbot P. Identification of toxicants in cinnamon-flavored electronic cigarette refill fluids. Toxicol Vitro Int J Publ Assoc BIBRA. 2013 Oct 25.

29. Kreiss K, Gomaa A, Kullman G, Fedan K, Simoes EJ, Enright PL. Clinical bronchiolitis obliterans in workers at a microwave-popcorn plant. N Engl J Med. 2002; 1;347:330-8.

30. Boylstein R, Piacitelli C, Grote A, Kanwal R, Kullman G, Kreiss K. Diacetyl emissions and airborne dust from butter flavorings used in microwave popcorn production. J Occup Environ Hyg. 2006;3:530-5.

31. European Parliament and Council. Commission implementing regulation (EU) No 793/2012 of 5 September 2012 adopting the list of flavoring substances provided for by Regulation (EC) No 2232/96 of the European Parliament and of the Council, introducing it in Annex I to Regulation (EC) No 1334/2008 of the European Parliament and of the

Council and repealing Commission Regulation (EC) No 1565/2000 and Commission Decision 1999/217/EC. http://eur-lex.europa.eu/LexUriServ/LexUriServ.do?uri=OJ:L:2012:243:0001:0161:EN:PDF

32. Schober W, Szendrei K, Matzen W, Osiander-Fuchs H, Heitmann D, Schettgen T, et al. Use of electronic cigarettes (e-cigarettes) impairs indoor air quality and increases FeNO levels of e-cigarette consumers. Int J Hyg Environ Health. 2014;217:628-37.

33. Vansickel AR, Cobb CO, Weaver MF, Eissenberg TE. A clinical laboratory model for evaluating the acute effects of electronic "cigarettes": nicotine delivery profile and cardiovascular and subjective effects. Cancer Epidemiol Biomarkers Prev. 2010;19:1945-53.

34. Vansickel AR, Weaver MF, Eissenberg T. Clinical laboratory assessment of the abuse liability of an electronic cigarette. Addiction. 2012;107:1493-500.

35. Vansickel AR, Eissenberg T. Electronic cigarettes: effective nicotine delivery after acute administration. Nicotine Tob Res. 2013;15:267-70

36. St Helen G, Havel C, Dempsey D, Jacob P, Benowitz NL. Nicotine delivery, retention, and pharmacokinetics from various electronic cigarettes. Addiction. 2016;111:535-44 doi: 10.1111/add.13183. 
37. McNeill A, Brose LS, Calder R, Hitchman SC for Public Health England E-cigarettes: an evidence update. PHE publications $\quad$ gateway $\quad$ number: $2015260 \quad$ PDF, $\quad 2.07 \mathrm{MB}, \quad 113 \quad$ pages https://www.gov.uk/government/uploads/system/uploads/attachment_data/file/457102/Ecigarettes_an_evidence_updat e_A_report_commissioned by_Public_Health_England_FINAL.pdf

38. Goniewicz ML, Knysak J, Gawron M, Kosmider L, Sobczak A, Kurek J, et al. Levels of selected carcinogens and toxicants in vapor from electronic cigarettes. Tob Control. 2014;23:133-9.

39. Farsalinos KE, Voudris V, Poulas K. E-cigarettes generate high levels of aldehydes only in "dry puff” conditions. Addiction. 2015;110:1352-6 doi:10.1111/add.1294

40. ANSES Valeurs guides de qualité d'air intérieur : Le formaldéhyde ANSES 2007 France.

41. ANSES Valeurs guides de qualité d'air intérieur : L'acetaldéhyde 2014 France

42. Jensen RP, Luo W, Pankow JF, Strongin RM, Peyton DH. Hidden formaldehyde in e-cigarette aerosols. N Engl J Med. 2015;372: 392-4. doi:10.1056/NEJMc1413069. PubMed PMID: 25607446.

43. EMEA CHMP 2007 Guideline on the specification limits for residues of metal catalysts http://www.ema.europa.eu/docs/en_GB/document_library/Scientific_guideline/2009/09/WC500003587.

44. Dautzenberg B., Bricard D. Real-Time Characterization of E-Cigarettes Use: The 1 Million Puffs Study. J Addict Res Ther 2015; 6: 229.

http://www.omicsonline.org/open-access/realtime-characterization-of-ecigarettes-use-the-1-million-puffs-study-21556 105-1000229.pdf

45. Mason DP, Subramanian S, Nowicki ER, Grab JD, Murthy SC, Rice TW, Blackstone EH. Impact of smoking cessation before resection of lung cancer: a Society of Thoracic Surgeons General Thoracic Surgery Database study.Ann Thorac Surg. 2009;88:362-70. doi: 10.1016/j.athoracsur.2009.04.035.

46. Jung KH, Kim SM, Choi MG, Lee JH, Noh JH, Sohn TS, Bae JM, Kim S. Preoperative smoking cessation can reduce postoperative complications in gastric cancer surgery.Gastric Cancer. 2015;18:683-90. doi:

$10.1007 / \mathrm{s} 10120-014-0415-6$ 
47. Alsadius D, Hedelin M, Johansson KA, Pettersson N, Wilderäng U, Lundstedt D, Steineck G. Tobacco smoking and long-lasting symptoms from the bowel and the anal-sphincter region after radiotherapy for prostate cancer. Radiother Oncol. 2011;101:495-501. doi: 10.1016/j.radonc.2011.06.010

48. Wedlake LJ, Thomas K, Lalji A, Blake P, Khoo VS, Tait D, Andreyev HJ.Predicting late effects of pelvic radiotherapy: is there a better approach? Int J. Radiat Oncol Biol Phys. 2010 15;78:1163-70. doi:10.1016/j.ijrobp.2009.09.011.

49. Parsons AI, Daley A, Begh R, Aveyard P.Influence of smoking cessation after diagnosis of early stage lung cancer on prognosis: systematic review of observational studies with meta-analysis. BMJ. 2010 Jan 21;340:b5569. doi: 10.1136/bmj.b5569.

50. Travis LB, Gospodarowicz M, Curtis RE, Clarke EA, Andersson M, Glimelius B, et al. Lung cancer following chemotherapy and radiotherapy for Hodgkin's disease. J Natl Cancer Inst. 2002;94:182-92.

51. Gilbert ES, Stovall M, Gospodarowicz M, Van Leeuwen FE, Andersson M, Glimelius B, et al. Lung cancer after treatment for Hodgkin's disease: focus on radiation effects. Radiat Res. 2003;159:161-73.

52. Ford MB, Sigurdson AJ, Petrulis ES, Ng CS, Kemp B, Cooksley C, McNeese M, et al Effects of smoking and radiotherapy on lung carcinoma in breast carcinoma survivors. Cancer. 2003;98:1457-64.

53. Prochazka M, Hall P, Gagliardi G, Granath F, Nilsson BN, Shields PG, et al. Ionizing radiation and tobacco use increases the risk of a subsequent lung carcinoma in women with breast cancer: case-only design. J Clin Oncol. 2005 $20 ; 23: 7467-74$.

54. Poghosyan H, Sheldon LK, Leveille SG, Cooley ME. Health-related quality of life after surgical treatment in patients with non-small cell lung cancer: a systematic review. Lung Cancer. 2013;81:11-26. doi:

10.1016/j.lungcan.2013.03.013.

55. Barton, M. K. Electronic cigarettes did not help patients with cancer stop smoking. CA: A CA Cancer J Clin 2015 ;65:85-6. doi: 10.3322/caac.21264.

56. Fillon M. Electronic cigarettes might not help cancer patients quit smoking. Journal of the National Cancer Institute 2015;107: 496. 
57. Cummings KM, Dresler CM, Field JK, Fox J, Gritz ER, Hanna N et al. E-cigarettes and cancer patients. Journal of Thoracic Oncology 2014; 9: 438-41. http://www.ncbi.nlm.nih.gov/pubmed/24736063

58. Borderud SP, Li Y, Burkhalter JE, Sheffer CE, Ostroff JS. Electronic cigarette use among patients with cancer: characteristics of electronic cigarette users and their smoking cessation outcomes. Cancer. 2014;120:3527-35. doi: 10.1002/cncr.28811. Erratum in: Cancer. $2015 \quad$ 1;121:800. PMID: 25252116. http://www.ncbi.nlm.nih.gov/pubmed/25252116

59. Born H., Persky M., Kraus DH., Peng R., Amin MR and Branski RC. Electronic cigarettes: a primer for clinicians. Otolaryngology - Head and Neck Surgery. 2015 153:5-14 http://www.ncbi.nlm.nih.gov/pubmed/26002957

60. Brandon TH, Goniewicz ML, Hanna NH, Hatsukami DK, Herbst RS, Hobin JA, et al. Electronic Nicotine Delivery Systems: A Policy Statement from the American Association for Cancer Research and the American Society of Clinical Oncology. Clinical Cancer Research . 2015; 21:514-25 http://www.ncbi.nlm.nih.gov/pubmed/25573384

61. Cummings KM, Dresler CM, Field JK, Fox J, Gritz ER, Hanna NH, Ikeda N, Jassem, J, Mulshine JL, Peters MJ, Yamaguchi NH, Warren G, Zhou C. E-cigarettes and cancer patients. J Thorac Oncol. 2014;4:438-41. doi: 10.1097/JTO.0000000000000129. PubMed PMID: 24736063;

62. Dautzenberg B, Adler M, Garelik D, Loubrieu JF, Peiffer G, Perriot J et all.. Adaptations to the management of smoking cessation with the arrival of e-cigarette? Expert opinion from the Office français de prévention du tabagisme (OFT) 2014. Rev Mal Respir. 2014 ;31:641-5. doi: 10.1016/j.rmr.2014.06.005

63. McRobbie H, Bullen C, Hartmann-Boyce J, Hajek P. Electronic cigarettes for smoking cessation and reduction. Cochrane Database Syst Rev. 2014;12:CD010216. doi: 10.1002/14651858.CD010216.pub2. 


\section{Legend of figure}

Fig 1: Diagram of an e-cigarette

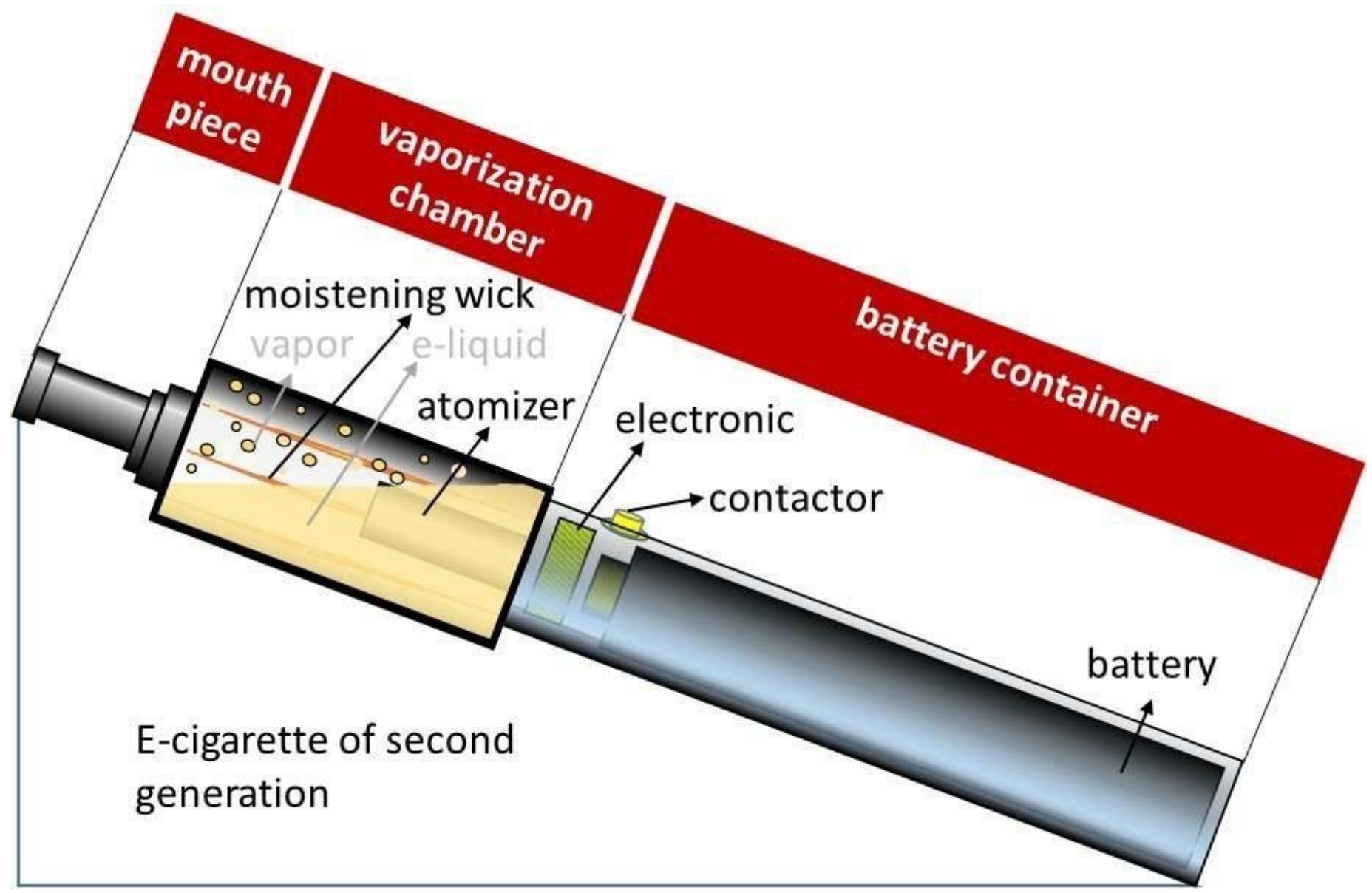


Table 1: How health professional may help to cancer patient

\begin{tabular}{|lll|}
\hline non-smoker or former smoker 1 year & $\rightarrow$ & prevent e-cigarette use \\
\hline daily smoker with lung cancer who don't & $\rightarrow$ & consider e-cigarette as a product close to oral NRT to decrease \\
went or succeed to stop to smoke & & craving to tobacco and reduce (before to stop) \\
\hline $\begin{array}{l}\text { dual users (tobacco + e-cigarette) } \\
\text { very long term e-cigarette user, former }\end{array}$ & $\begin{array}{l}\text { increase intake of non-tobacco nicotine (add a patch }+ \\
\text { increase intake of nicotine from e-cigarette }\end{array}$ \\
\hline smoker & consider reduction of e-cigarette only if craving for tobacco is \\
\end{tabular}

